\title{
HLA antigens and myasthenia gravis in north India
}

\author{
NK MEHRA, ${ }^{*}$ GK AHUJA, $\dagger$ V TANEJA, ${ }^{*}$ MC VAIDYA* \\ From the Department of Anatomy* (Cellular Immunology Laboratory) and Department of Neurology, $\dagger$ All \\ India Institute of Medical Sciences, New Delhi, India
}

SUMMARY The HLA antigen distribution was studied in 37 north Indian patients with myasthenia gravis. The control group consisted of 118 normal, healthy individuals of the same ethnic group. The antigens showing the highest frequency were Bw21 (18.9\% vs $4.2 \% \mathrm{p}<0.005)$, Bw35 $(24.3 \%$ vs $6.8 \%, \mathrm{p}<0.005)$ and A9 $(51.3 \%$ vs $30.5 \%, \mathrm{p}<0.025)$. HLA-B8 was increased nearly two fold in the myasthenia gravis patients $(R R=2.4)$ and was confined mainly to the young females without thymoma. The possibility that Bw21 and Bw35 might be the markers for susceptibility to autoimmune disorders in India is discussed. The observations also support those of others that HLA-B8 linked susceptibility gene is more frequently found in myasthenia gravis patients with thymic hyperplasia.

Epidemiological observations on myasthenia gravis have indicated the familial nature of this disease. ${ }^{1}$ However, the pattern of inheritance and the pathogenetic significance of the autoantibodies in myasthenic patients are not clear. Several groups have tried to establish the association of myasthenia gravis with HLA antigens. Most of these investigations have been done in individuals of Caucasian origin. A constant finding has been the increased frequency of HLA-B8 antigen particularly in the young females. ${ }^{2-5}$ Others, while confirming the association of $\mathrm{B} 8$ in female patients, reported the association of HLA-A3 or HLA-A2 in male patients with thymoma or with late onset of disease. ${ }^{67}$ Both these groups of workers, however, reported decrease of HLA-B7 in myasthenia gravis. This led investigators to believe that there might be two forms of the disease and that their inheritance may be under polygenic control. There is as yet no data available on HLA and myasthenia gravis in Indian patients. This along with our own findings on the association of HLA-Bw21 and Bw35, rather than $B 8$ in patients of insulin-dependent diabetes mellitus ${ }^{8}$ prompted us to undertake HLA studies in

\footnotetext{
Address for reprint requests: Dr GK Ahuja, Associate Professor of Neurology, All India Institute of Medical Sciences, New Delhi110029, India.
}

Received 30 April 1982 and in revised form 8 October 1982 Accepted 20 November 1982 myasthenia gravis patients. The known race specificity of the HLA and disease association provided further impetus for such studies.

\section{Material and methods}

Thirty seven unrelated north Indian patients with myasthenia gravis attending the Neurology clinic of the All India Institute of Medical Sciences Hospital, New Delhi were selected for the study. Ethnically, they represented north Indian Hindus belonging to the states of Punjab, Haryana, Uttar Pradesh and Delhi. The diagnosis of myasthenia gravis was made on compatible clinical picture and was confirmed by unequivocal response to prostigmin test. The diagnosis was further supported by decremental response to repeated nerve stimulation and stapedius reflex.9 All patients had radiographs of the chest, with postero-anterior and lateral views taken for evidence of thymoma. Chest tomography was done whenever the plain radiographs revealed equivocal evidence of thymoma. All patients with thymoma were subjected to thymectomy and the diagnosis verified histologically.

The control group for comparison consisted of 118 unrelated healthy persons of the same racial and ethnic background. HLA typing for the detection of antigens in the HLA-A and B loci was performed using the two stage NIH microlymphocytoxicity test with slight modifications. ${ }^{10}$ The antisera for typing were supplied by the kind courtesy of Prof Jon Van Rood, Europtransplant Foundation, Leiden and the NIH serum bank, USA.

Relative risk (RR) for a particular antigen was calculated by the formula

$$
R R=\frac{a \times d}{b \times c},
$$


where $a$ and $b$ are the number of patients with or without the antigen respectively, and $\mathrm{c}$ and $\mathrm{d}$ are the corresponding numbers of controls. The percent phenotype frequencies of antigens in patients and controls were compared on a $2 \times 2$ table using Yates' correction.

\section{Results}

Table 1 shows the percent HLA antigen frequencies in patients and controls along with the relative risk for each antigen. The frequency of HLA-Bw21, Bw35 and A9 was significantly increased in the patient group as against the controls. Bw21 presented the highest relative risk of 5.0 in our series of patients. HLA-B8 was increased nearly two fold in the myasthenia gravis patients $(R R=2 \cdot 4)$ but did not reach statistical significance. Antigen HLA-B7 was present with a decreased frequency in the patient group (8.1\%) as compared to the controls $(22.9 \%),\left(\chi^{2}=3.93, \mathrm{p}=0.05\right)$. HLA-A2 and A3 did not demonstrate any significant deviation in myasthenia gravis patients as compared to controls.

Striking differences were observed when the thymoma and the non-thymoma group of patients were analysed separately for their HLA antigen distribution (table 2). Only HLA-Bw35 was raised in both the groups. There was a strong association with HLA-B8 and Bw21 in only those patients who did not have thymoma. Antigen B8 was present in eight out of the 25 patients in this group (frequency $32 \%$ ). This is statistically significant when compared to the B8 frequency of $11.9 \%$ in the controls. Seven out of these eight patients were females with onset of disease below 30 years. In the thymoma group,

Table 1 Percent HLA antigen frequencies in patients with myasthenia gravis in north India: $A$ and $B$ loci

\begin{tabular}{|c|c|c|c|c|c|c|}
\hline \multirow{2}{*}{$\begin{array}{l}H L A \\
\text { specificity }\end{array}$} & \multicolumn{2}{|c|}{ Patients $(N=37)$} & \multicolumn{2}{|c|}{ Controls $(N=118)$} & \multirow{2}{*}{$\begin{array}{l}\text { Relative } \\
\text { risk }\end{array}$} & \multirow[t]{2}{*}{$p$ value } \\
\hline & Number & $\%$ & Number & $\%$ & & \\
\hline $\begin{array}{l}\text { HLA-A1 } \\
\text { A2 } \\
\text { A3 } \\
\text { A9 } \\
\text { A10 } \\
\text { A11 } \\
\text { A28 } \\
\text { A29 } \\
\text { Aw30 } \\
\text { Aw31 } \\
\text { Aw32 } \\
\text { Aw33 } \\
\text { B5 } \\
\text { B7 } \\
\text { B8 } \\
\text { B12 } \\
\text { B13 } \\
\text { B14 } \\
\text { B15 } \\
\text { Bw16 } \\
\text { B17 } \\
\text { B18 } \\
\text { Bw21 } \\
\text { Bw22 } \\
\text { B27 } \\
\text { Bw35 } \\
\text { B37 } \\
\text { B40 }\end{array}$ & $\begin{array}{r}7 \\
9 \\
6 \\
19 \\
8 \\
11 \\
5 \\
4 \\
2 \\
2 \\
1 \\
0 \\
15 \\
3 \\
9 \\
5 \\
0 \\
0 \\
6 \\
2 \\
9 \\
1 \\
7 \\
3 \\
1 \\
9 \\
1 \\
4\end{array}$ & $\begin{array}{r}18 \cdot 9 \\
24 \cdot 3 \\
16 \cdot 2 \\
51 \cdot 3 \\
21 \cdot 6 \\
29 \cdot 7 \\
13 \cdot 5 \\
10 \cdot 8 \\
5 \cdot 4 \\
5 \cdot 4 \\
2 \cdot 7 \\
0 \cdot 0 \\
40 \cdot 5 \\
8 \cdot 1 \\
24 \cdot 3 \\
13 \cdot 5 \\
0 \cdot 0 \\
0 \cdot 0 \\
16 \cdot 2 \\
5 \cdot 4 \\
24 \cdot 3 \\
2 \cdot 7 \\
18 \cdot 9 \\
8 \cdot 1 \\
2 \cdot 7 \\
24 \cdot 3 \\
2 \cdot 7 \\
10 \cdot 8\end{array}$ & $\begin{array}{r}31 \\
33 \\
25 \\
36 \\
18 \\
22 \\
17 \\
13 \\
4 \\
3 \\
9 \\
1 \\
34 \\
27 \\
14 \\
25 \\
16 \\
0 \\
20 \\
0 \\
27 \\
5 \\
5 \\
4 \\
7 \\
8 \\
3 \\
26\end{array}$ & $\begin{array}{r}26 \cdot 3 \\
28 \cdot 0 \\
21 \cdot 2 \\
30 \cdot 5 \\
15 \cdot 3 \\
18 \cdot 6 \\
14 \cdot 4 \\
11 \cdot 0 \\
3 \cdot 4 \\
2 \cdot 5 \\
7 \cdot 6 \\
0 \cdot 8 \\
28 \cdot 8 \\
22 \cdot 9 \\
11 \cdot 9 \\
21 \cdot 2 \\
13 \cdot 6 \\
0 \cdot 0 \\
17 \cdot 0 \\
0 \cdot 0 \\
22 \cdot 8 \\
4 \cdot 2 \\
4 \cdot 2 \\
3 \cdot 4 \\
5 \cdot 9 \\
6 \cdot 8 \\
2 \cdot 5 \\
22 \cdot 0\end{array}$ & $\begin{array}{l}0.65 \\
0.82 \\
0 \cdot 72 \\
2.40 \\
1 \cdot 50 \\
1.85 \\
0.92 \\
0.98 \\
1 \cdot 62 \\
2 \cdot 10 \\
0.34 \\
1 \cdot 68 \\
0 \cdot 29 \\
2.40 \\
0.58 \\
- \\
0.94 \\
1.0 \\
0.63 \\
5 \cdot 00 \\
2.51 \\
0.44 \\
4.00 \\
1 \cdot 06 \\
0.43\end{array}$ & $<0.025$ \\
\hline
\end{tabular}

Table 2 Percent HLA antigen frequencies in thymoma and non-thymoma group of patients

\begin{tabular}{|c|c|c|c|c|c|}
\hline \multirow{2}{*}{$\begin{array}{l}H L A \\
\text { antigen }\end{array}$} & \multirow{2}{*}{$\begin{array}{l}\text { Controls } \\
\text { (118) }\end{array}$} & \multicolumn{2}{|c|}{ Thymoma (12) } & \multicolumn{2}{|c|}{ Non-thymoma (25) } \\
\hline & & Freq & $p$ value & Freq & $p$ value \\
\hline $\begin{array}{c}\text { HLA-A9 } \\
\text { B7 } \\
\text { B8 } \\
\text { B15 } \\
\text { Bw21 } \\
\text { Bw35 }\end{array}$ & $\begin{array}{r}30 \cdot 5 \\
22.9 \\
11.9 \\
17 \cdot 0 \\
4 \cdot 2 \\
6.8\end{array}$ & $\begin{array}{r}75 \cdot 0 \\
8 \cdot 3 \\
8 \cdot 3 \\
16 \cdot 7 \\
16 \cdot 7 \\
25 \cdot 0\end{array}$ & $\begin{array}{l}p<0.005 \\
\text { NS } \\
\text { NS } \\
\text { NS } \\
\text { NS } \\
p<0.05\end{array}$ & $\begin{array}{r}40 \cdot 0 \\
8 \cdot 0 \\
32 \cdot 0 \\
16 \cdot 0 \\
20 \cdot 0 \\
24 \cdot 0\end{array}$ & $\begin{array}{l}\text { NS } \\
\text { NS } \\
p<0.025 \\
\text { NS } \\
p<0.005 \\
p<0.01\end{array}$ \\
\hline
\end{tabular}

NS $=$ not significant. 
HLA-A9 showed the highest phenotype frequency of $75 \%$ as compared to $30.5 \%$ in the control group. Both B8 as well as Bw21 did not show any association in this group. The only B8 positive patient with thymoma was a female in whom the first symptoms of myasthenia were observed at the age of 40 years.

\section{Discussion}

The association of HLA-B8 in Caucasian female patients with an early onset of myasthenia gravis is well established..$^{5}$ This study which is the first report on the HLA antigen distribution in north Indian patients with myasthenia gravis indicates that it is strongly associated with HLA-Bw21 (19\% vs $4 \%$, $\mathrm{RR}=5)$ and $\mathrm{Bw} 35(24 \%$ vs $7 \%, \mathrm{RR}=4)$, HLA-B8 was increased nearly two fold $(R R=2.4)$ but did not reach statistical significance. This association of $\mathrm{Bw} 21$ and $\mathrm{Bw} 35$ with myasthenia gravis seems to be specific to the Indian population since the frequency of these antigens in the normal population does not differ significantly in Indians in comparison with Caucasians. ${ }^{11}$ In a recent study of the Japanese myasthenics, Yoshida et al $^{12}$ reported an increased incidence of HLA-B12 especially in young females with early disease and thymic hyperplasia. These studies, therefore, emphasise the race specificity of the HLA and disease associations.

Besides myasthenia gravis, HLA-B8 has been reported to be associated with many other autoimmune disorders in Caucasians such as diabetes mellitus, thyrotoxicosis, Addison's disease, coeliac disease. ${ }^{13}$ Our earlier studies on Insulin-dependent diabetes mellitus (Type I) conducted on patients of north Indian origin revealed an association with $\mathrm{Bw} 21$ and Bw35 rather ran with $\mathrm{B} 8 .^{8}$ It is possible that in a population like the one under consideration, Bw21 and Bw35 can apparently play the same role as genetic marker as $\mathrm{B} 8$ in Caucasians at least so far as the autoimmune disorders are concerned. The similarity in the negative association with HLA-B7 in Caucasians and north Indians indicates that the B-allele conferring protection in myasthenia gravis might be common in several populations.

The observed increased frequency of B8 in the non-thymoma group of patients particularly the females with an early onset of the disease support the hypothesis that the B8 linked susceptibility gene is more frequently found among myasthenia gravis patients with thymic hyperplasia and is related to the early age of onset. Whether this has any influence of the sex-linked factors is not certain since studies exclusively on male myasthenia gravis patients have suggested that the association with B8 is equally strong in males particularly those with age of onset below 35 years. $^{14}$
The increased frequency of A9 in north Indian myasthenia gravis patients with thymoma is quite striking. It is of interest that others have reported an excess of $\mathrm{A} 2$ and $\mathrm{A} 3$ in their patients with thymoma. ${ }^{67}$ These observations suggest that other MHC-linked genetic factors play a key role in susceptibility to myasthenia gravis. Moreover, family studies by Dick $e a^{3}$ have demonstrated amply that B8 is not an essential pre-requisite for the development of the disease and that B8 homozygosity does not in any way enhance the risk of developing myasthenia gravis. It appears, therefore, that though B8 or other B-locus antigens (Bw21 and Bw35 in north Indians) clearly increase one's susceptibility to develop myasthenia gravis, other factors including environmental play a significant role. It is thus logical to conclude that myasthenia gravis occurs as a result of an interaction between multiple host genetic and environmental influences.

The authors thank Prof. Jon van Rood, Leiden and the NIH serum Bank, USA for the supply of HLA antisera. The study was supported by grants from the Indian Council of Medical Research (ICMR), New Delhi.

\section{References}

${ }^{2}$ Kurland LT, Alter M. Current status of the epidemiology and genetics of myasthenia gravis. In: Viets HR, ed. Myasthenia Gravis. Springfield: Thomas, 1961:307-36.

${ }^{2}$ Safwenberg J, Lindblom JB, Osterman PO. HLA frequencies in patients with myasthenia gravis. Tissue Antigens 1973;3:465-9.

${ }^{3}$ Dick HM, Behan PO, Simpson JA, Durward WF. The inheritance of HLA antigens in myasthenia gravis. $J$ Immunogenet 1974;1:401-12.

${ }^{4}$ Pirakanen R. Genetic association between myasthenia gravis and the HL-A system. J Neurol Neurosurg Psychiatry 1976;39:23-33.

5 Behan PO. Immune disease and HLA associations with myasthenia gravis. J Neurol Neurosurg Psychiatry 1980;43:611-21.

' Fritz D, Herman C Jr, Naeim F, Smith GS, Walford RL. HLA antigens in myasthenia gravis. Lancet $1974 ; 1: 240-43$.

${ }^{7}$ Feltkemp TW, van den Berg-Loonen PH, Nijenhuis LE, et al. Myasthenia gravis, autoantibodies and HLA antigens. $\mathrm{Br}$ Med $J$ 1974;1:131-3.

${ }^{8}$ Srikantha S, Mehra NK, Vaidya MC, Malviya AN, Ahuja MMS. HLA antigens in type I (insulindependent) diabetes mellitus in north India. Metabolism 1981;30:992-3.

9 Ahuja GK, Verma A, Ghosh P, Nagaraj MN. Stepedius reflexometry. A diagnostic test of myasthenia gravis. $J$ Neurol Sci 1980;46:311-4. 
${ }^{10}$ Terasaki PI, McCleland JD. Microdroplet assay of human serum cytotoxins. Nature 1964;204:998-1000.

${ }^{11}$ Nerup J, Cathelineau Cr, Seignalet J, Thomsen M. HLA and endocrine disease. In: Deusset J, Svejgaard A, eds. HLA and disease. Copenhagen: Munksgaard, 1977:149-67.

12 Yoshida T, Tsuchiya M, Ono A, Yoshimatsu H,
Satoyoshi E, Tsuji K. HLA antigens and myasthenia gravis in Japan. J Neurol Sci 1977;32:195-201.

${ }^{13}$ Eddleston ALWF, Williams R. HLA and liver disease. Br Med Bull 1978;34:295-300.

${ }^{14}$ Safwenberg J, Hammerstrom L, Lindblom JB, et al. HLA-A, -B, -C and -D antigens in male patients with myasthenia gravis. Tissue Antigens 1978;12:136-42. 